East African Journal of Science, Technology and Innovation, Vol. 2 (4): September 2021

This article is licensed under a Creative Commons license, Attribution 4.0 International (CC BY 4.0)

\title{
Antimicrobial resistance phenotypes of Staphylococcus aureus and Coagulase negative Staphylococci species isolated from raw camel milk from Garissa County, Kenya
}

\author{
1*KIRWA E., ${ }^{1}$ ABOGE G O., ${ }^{1}$ MAITHO TE., ${ }^{2 M B I N D Y O ~ C M ., ~}{ }^{3}$ ABUOM T O., 1 MAINGA A O \\ ${ }^{1}$ College of Agriculture and Veterinary Sciences, Department of Public Health, Pharmacology and Toxicology University of Nairobi, \\ P.O. Box 29053-00625, Kangemi, Nairobi, Kenya \\ ${ }^{2}$ College of Agriculture and Veterinary Sciences, Department of Veterinary Pathology, Microbiology and Parasitology, Univ ersity of \\ Nairobi. P.O. Box 29053-00625, Kangemi, Nairobi, Kenya \\ ${ }^{3}$ College of Agriculture and Veterinary Sciences, Department of Clinical Studies, University of Nairobi P.O. Box 29053-00625, \\ Kangemi, Nairobi, Kenya \\ *Corresponding author: dr.kipchumba@gmail.com
}

\section{Abstract}

The emergence of multidrug resistant bacteria in clinically challenging situations is a global concern. Staphylococcus resistance poses a threat to available therapeutic agents in management of camel diseases. S. aureus is often isolated from mastitic camel milk. Coagulase negative Staphylococcus (CoNS) can be pathogenic in humans and animals. This study investigated the antimicrobial resistance phenotypes of Staphylococci species in raw camel milk from Garissa County, Kenya. A total of 231 raw camel milk samples from healthy camels were collected. Disk diffusion was used to determine antimicrobial susceptibility of the isolates. Bacteria were revived in Buffered Peptone Water (BPW). Staphylococcus isolates were cultured on Mannitol Salt agar (MSA) and Blood Agar (BA). Coagulase and catalase tests were used to biochemically characterize the isolates. Antibiotic disks were placed on Mueller Hinton Agar and incubated at $37^{\circ} \mathrm{C}$ for 24 hours and diameters of zones inhibition measured. The readings were recorded as either susceptible, intermediate, or resistant based on the interpretative breakpoints by the veterinary Clinical Laboratory Standards Institute (CLSI) guidelines. Antimicrobial agents tested included; Ampicillin, Streptomycin, Cephalexin, Erythromycin, Ciprofloxacin, Cefoxitin, Tetracycline and Chloramphenicol. Out of the 231 raw camel milk samples cultured, 52.8\% (122/231) Staphylococci isolates were recovered. Among the Staphylococci isolates $83.6 \%$ (102) were S. aureus and $16.4 \%$ (20) were CoNS. Overall, 83 (68\%) isolates were catalase positive and $122(91.7 \%)$ showed $\beta$-haemolysis on BA culture. Highest resistance was observed against Cephalexin $(81.9 \%)$ and Streptomycin $(72.1 \%)$ while the lowest resistance was seen against Chloramphenicol (1.6\%) and Tetracycline (3.3\%). MRSA and MRCoNS were reported at $9.8 \%$ and $15 \%$ of the isolates respectively. MDR was recorded in $43.4 \%$ of the isolates resistant to at least 3 or more antimicrobial groups while $39.3 \%$ isolates were resistant to 1 or 2 antimicrobial tested. In conclusion, the study showed that CoNS and S. aureus isolates coexist contaminating raw camel milk and are highly resistant to Cephalexin and Streptomycin. Continuous monitoring of resistance is recommended in order to prevent the spread of AMR.

Keywords: Coagulase negative Staphylococcus; Staphylococcus aureus; Multidrug resistance; camel

Cite as: Kirwa et al., (2021). Antimicrobial resistance phenotypes of Staphylococcus aureus and Coagulase negative Staphylococci species isolated from raw camel milk from Garissa County, Kenya. East African Journal of Science, Technology and Innovation 2(4).
Received:

Accepted: Published:
$30 / 05 / 21$

$19 / 08 / 21$

25/09/21 


\section{Introduction}

Staphylococci bacteria are gram positive, nonmotile, encapsulated cocci occurring in pairs, short chains or singly (Ryan and Ray, 2004). They are found on varied surfaces in the environment including the skin and mucous membranes of warm-blooded mammals as commensals and in soil, sand, air and water as well as animal sourced proteins (Zdolec et al., 2015). Staphylococci are grouped into coagulase-positive Staphylococcus (CoPS), mainly S. aureus and coagulase-negative Staphylococcus (CoNS) by their ability to produce coagulase (Bennet et al., 2013; De Buck et al., 2021).

S. aureus causes a variety of infections affecting the skin and soft tissue including pneumonia and joint infections (Becker et al., 2014). The organism also cause toxin-mediated diseases through ingestion or entry into the bloodstream resulting in toxin-mediated diseases such as toxic-shock syndrome (TSS), scalded-skin syndrome (SSS) and food poisoning (Spaulding et al., 2013).

CoNS are considered commensals on skin and mucosal membranes of humans and animals. However, these organisms are opportunistic pathogens which cause disease when there is a breach on skin or mucus membranes (Schoenfelder et al, 2010). Recent studies have however indicated that CoNS can directly or indirectly be pathogenic (Bhargava and Zhang, 2012).

In animals, $S$. aureus and CoNS have been reported to cause mastitis, septicemia and arthritis in poultry (Simojoki et al., 2011; Sampimon et al., 2011). CoNS are increasingly being recognized as an important cause of mastitis in cattle in Kenya, Tanzania, Egypt, Tunisia, Czech Republic and other parts of the world including Europe, South America and the Middle East (Mbindyo et al., 2020; Soares et al., 2012; El-Razik et al., 2017; Srednik et al., 2017; Pyatov et al., 2017 and Melo et al., 2018).

Mastitis is a significant constraint to camel production in various parts of the world, including Kenya, Tunisia, Ethiopia, Pakistan and Middle East (Wanjohi et al., 2013; Toroitich et al., 2017; Klibi et al., 2018) through money spent in management of the infection as well as deaths in severe cases. Mastitis has also been reported to have zoonotic potential through development and spread of multidrug resistant pathogens (Beyene et al., 2017).

In humans, CoNS is an opportunistic pathogen which is involved in catheter-related infections, osteomyelitis, bacteremia, endocarditis and urinary tract infections (Feßler et al., 2010). Staphylococci pathogens account for $30 \%$ of nosocomial infections with $S$. aureus and $S$. epidermidis being commonly isolated CoPS and CoNS respectively (Otto, 2013).

Most of the antimicrobial agents used in treatment of mastitis are also used in humans (Toutain et al., 2016). For example, tetracyclines, lincosamides, beta lactams, flouroquinolones and aminoglycosides are used in the management of CoNS infections in human medicine and Veterinary practice (Argudin, 2017). This has resulted in significant rise of AMR nonpathogenic Staphylococcus and $S$. aureus. Antibiotic-resistant Staphylococcus bacteria mainly results from misuse and the ease of access to poor-quality antimicrobials (Mukokinya et al., 2018). The boundless utilization of antibiotics on dairy animals and other food-producing animals like camels also contributes to the AMR to CoNS, leading to severe threat to public health.

Microorganisms have developed various mechanisms to counter antimicrobials. These include global response to environmental stresses such as the oxidative stress response system, established mar-regulon among fluoroquinolone resistant isolates and the soxRS regulon of E. coli and Salmonella eterica (Demple, 2005). Biofilm formation acts as playgrounds for concentrating and conferring resistance traits. This is also advanced by plasmid mediated resistance interdependency and exchange of mobile genetic elements such as integrons, gene cassettes and transposons (Fey and Oslon, 2010). 
Surveillance of antimicrobial resistance in different regions of the world including Africa, America, Europe and the West Pacific have indicated significant evolution of microorganisms and the looming multidrug resistance (MDR) and resultant public health threat (Opintan et al., 2015; WHO, 2014; Van Kinh et al., 2017). Mechanisms of MDR include chromosomal mutations or conjugative exchange of extrachromosomal DNA elements which alter bacterial cell wall composition leading to lack of active target sites for microbial agents (Alexshun and Levey, 2007; WHO, 2014). The MDR phenotype is a characteristic of most Staphylococcus including the MRSA strains (Egyir et al., 2014).

CoNS have been found to be more often multidrug resistant than $S$. aureus and respond weakly to most therapeutic agents (Frey et al., 2013). The main adhesive matrix in the CoNS species is encoded for by a group of ses genes and the aae, at $\mathrm{E}, s d r \mathrm{G}$ and Embp genes, which have shown transmission of the same genes to pathogenic Staphylococcus (Christiner et al., 2010). CoNS increasing antibiotic resistance has also been attributed to various factors including injudicious antibiotic use (Srednik et al., 2017) as well as mecA mediated oxacillin resistance (Mahato et al., 2017) and biofilm forming genes (Srednik et al., 2017). Biofilms facilitate antimicrobial resistance by mediating attachment of host proteins resulting in expression of a cationic glucosamine-based exopolysaccharides that aggregates the bacterial cells (Otto, 2018).

Widespread Methicillin Resistant CoNS (MRCoNS) has been reported in nosocomial infections with the exception of S. lugdunensis for which its first resistance was reported in 2003 (Starlander et al., 2014). Kotsakis et al., 2011, described methicillin resistance by $S$. lugdunensis by mutational alteration of PBP1A/1B. The selection pressure within CoNS organisms has resulted in increased resistance to multiple antibiotics and biocidic compounds especially in hospitalized and recovered patients (Cherifi et al., 2013).

Recently, there are increased global reported cases of CoNS contamination of food, especially the methicillin resistant CoNS (Fowoyo and Ogunbanwo, 2017; Yang et al., 2017). For instance, bacteria isolated from raw camel milk in India showed both S. aureus and CoNS (Verma and Prakash, 2016), cow milk in Finland and Brazil (Simojoki et al., 2011; Soares et al., 2012) including animal protein sources in Poland (ChajęckaWierzchowska et al., 2015).

Omwenga et al., (2021) in their study on relationship between antimicrobial usage and emergence of multidrug-resistant (MDR) $S$. aureus in raw milk of livestock including camels in northern Kenya reported significant MRSA (94\%) with high resistance to beta lactams (58\%) and tetracyclines (78\%). In Africa, including Kenya, the role of non-pathogenic Staphylococci and $S$. aureus clones in camel milk is not well documented and therefore determining their antimicrobial resistance patterns may address this challenge that poses great threat to public health. In this study, antimicrobial resistance phenotypes of Staphylococcus species isolated from raw camel milk was investigated in Garissa County, Kenya.

\section{Materials and Methods}

\section{Ethical Approval}

The study was approved by the University of Nairobi, Faculty of Veterinary Medicine Biosafety, Animal Use and Ethics Committee in 2019 before the commencement of the study. Confidentiality was maintained throughout the study.

\section{Study area}

The study was conducted in the five SubCounties of Garissa County, located in the North eastern part of Kenya as shown in Figure 1. The County has a population of 623,060 people who solely depend on pastoralism as a major source of their livelihoods. Garissa County is one of the ASAL lands of Kenya and lies between IV-VI Agro ecological zones. The vast land is dry with a mean annual temperature of $28^{\circ}$ Cand less than $150 \mathrm{~mm}$ of rainfall annually (KNBS, 2010). Garissa County has a population of 234,683 camels (Toroitich. 2012). There has been a thriving camel milk business in Garissa County which supplies a significant amount of camel milk to Nairobi County. 


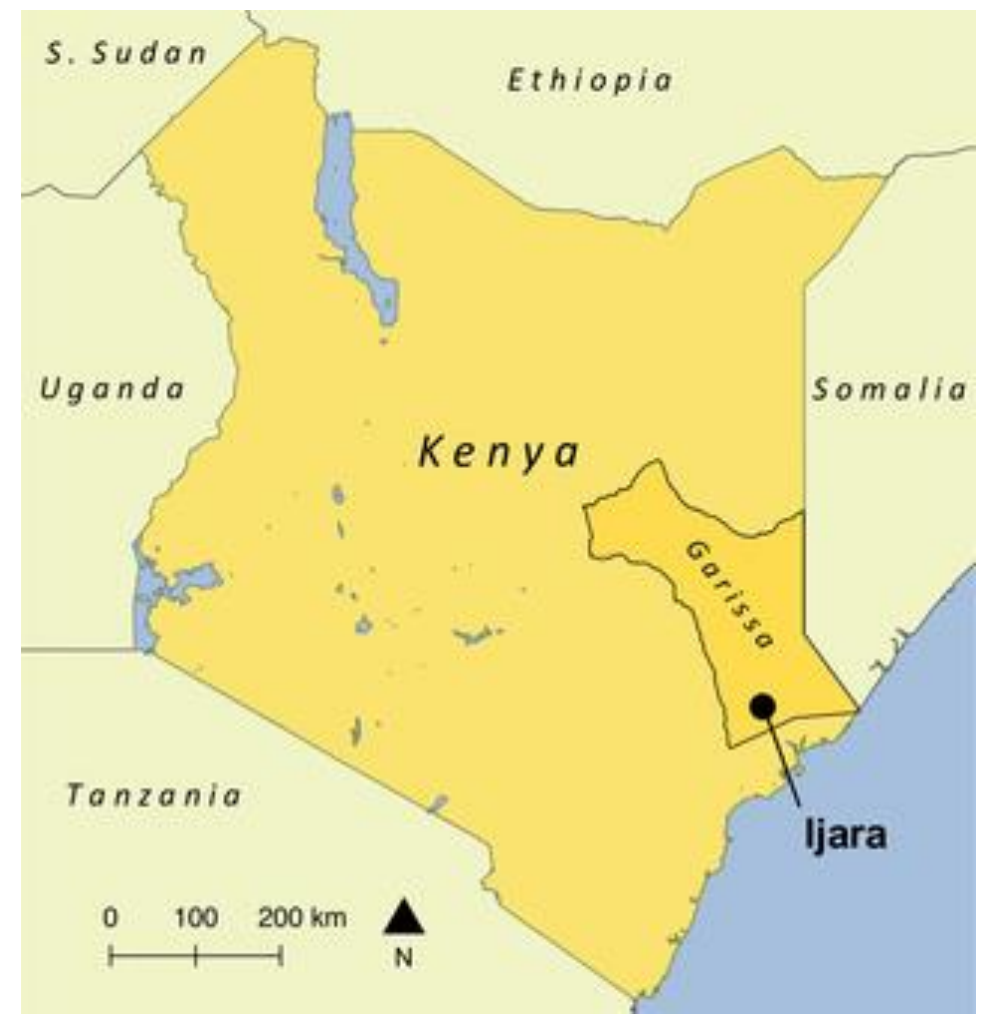

Figure 1: Map of Kenya showing the study area of Garissa County

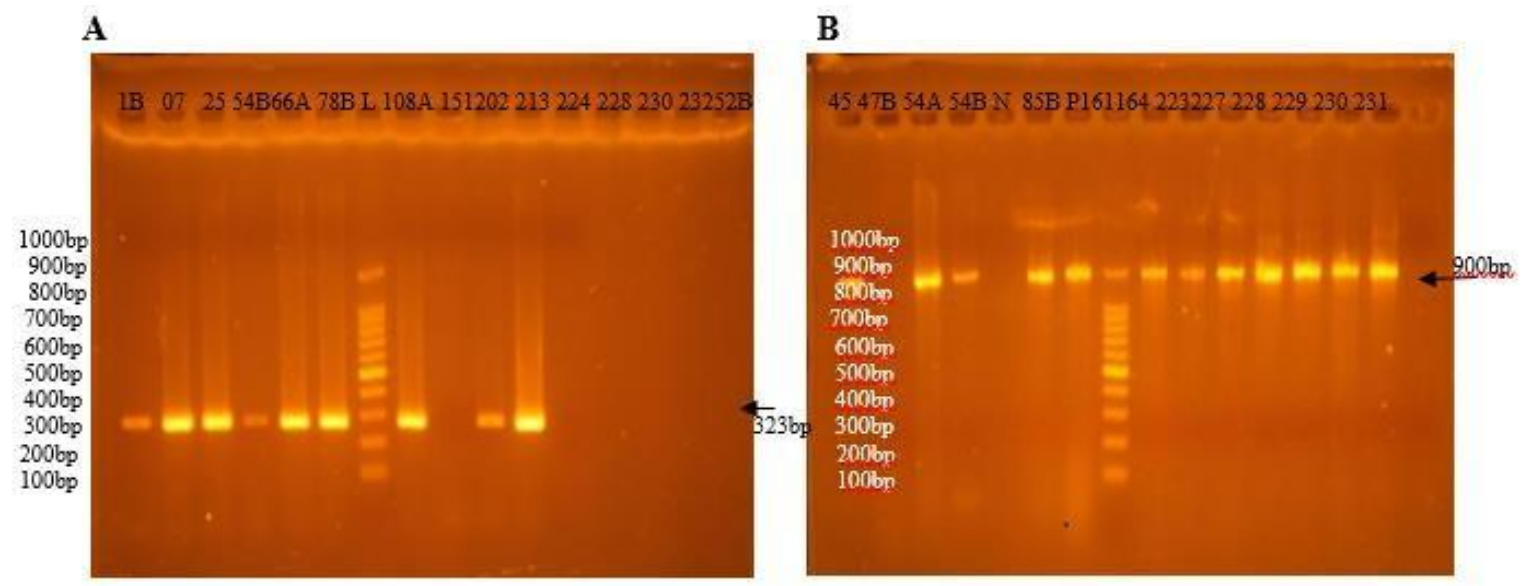

Figure 2. Polymerase chain reaction detection of Staphylococcus nuc gene

Figure 2: Conventional PCR amplification of Staphylococcus-16S rRNA gene and nuc gene fragment for identification of Staphylococcus species and particularly $S$. aureus in the isolates respectively. The PCR products were analyzed by gel electrophoresis on $1.5 \%$ agarose gel, stained with ethidium bromide. Gel image A shows nuc gene detection of Staphylococcus sp. at 323bp while gel image B shows isolate bands yielded by $16 \mathrm{~S}$ rRNA gene of $900 \mathrm{bp}$. Lane $\mathrm{L}$ is DNA ladder while Lane $\mathrm{P}$ is the positive standard of S. aureus ATCC ${ }^{2} 5923 \mathrm{TM}$, Lane N is negative control and the numbered lanes are the test samples. The lanes with no bands are samples negative for $n u c$ gene while the lanes with bands show the presence of the nuc gene indicating the presence of $\mathrm{S}$. aureus. The arrows show the positions of the amplified genes in gel 
A and B at 323bp and 900bp respectively

The PCR products were analyzed by gel electrophoresis on $1.5 \%$ agarose gel, stained with ethidium bromide. Gel image above shows nuc gene detection of Staphylococcus sp. at 323bp Lane $\mathrm{L}$ is DNA ladder while Lane $\mathrm{P}$ is the positive

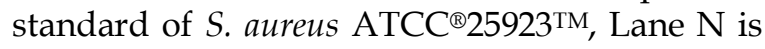
negative control and the numbered lanes are the test samples. The lanes with no bands are samples negative for nuc gene while the lanes with bands show the presence of the nuc gene indicating the presence of $S$. aureus. The arrow shows the position of the amplified gene at $323 \mathrm{bp}$.

\section{Study Animals and Study Design}

The study animals were lactating dromedary camels with apparently healthy udders. These were camels with no history of mastitis or any udder infection. Garissa County was purposively selected from the 47 counties in Kenya based on the high population of camels and the increasing market demand for camel milk in the neighboring counties especially Nairobi County.

A cross-sectional study with convenient sampling was done in the selected Sub-Counties in Garissa County. This involved exclusion criterion which included avoiding all nonlactating camels and clinically sick camels during milk sampling. Smallholder camel farmers were randomly selected from the list of camel farmers provided by the clan heads in each of the subCounties. Each farmer had to have at least two lactating camels and willing to participate in the study.

\section{Sample size determination}

The sample size for the study was determined using a formula described by Pfeiffer, (2013). n=Z2 P (1-P)/L2]; Where, $n=$ sample size, $\mathrm{Z}=$ the value of $\mathrm{z}$ that gives $95 \%$ confidence, with $25 \%$ expected prevalence (Younan et al., 2001), and $5 \%$ desired precision. $\mathrm{n}=\left(1.962^{*} 0.25^{*} 0.75\right) /$ (0.05)2. The number of samples per Sub County was proportional to the population of camels in that Sub County.

\section{Sample collection and preparation}

A total of 231 individual raw camel milk samples were collected aseptically from apparently healthy udders and samples were put in labeled sterile screw falcon tubes after discarding the first three streams of milk. This was performed by brushing loose dirt and hair from udder and teats followed by washing the teats and udders with water. The teats were then cleaned using cotton wool soaked with $70 \%$ ethanol. The milk samples were transported to the Department of Public Health Pharmacology and Toxicology of the University of Nairobi in cool boxes and cultured immediately on Mannitol Salt Agar.

\section{Isolation and Identification of Staphylococcus species}

The camel milk samples were enriched by inoculation in buffered peptone water (BPW) which was prepared by dissolving $10 \mathrm{~g}$ of powdered BPW in $500 \mathrm{mls}$ of distilled water. Thereafter, $1 \mathrm{ml}$ of each sample was added onto the $4 \mathrm{ml}$ aliquots of BPW and incubated at 370C overnight. Staphylococcus was isolated from raw camel milk samples using Mannitol Salt Agar (MSA) by methods described by Kateete et al., (2010) with slight modifications. This involved culture on MSA without the DNase test. Tube coagulase test was used to distinguish pathogenic from non-pathogenic Staphylococcus by inoculating a tube containing $0.5 \mathrm{ml}$ of rabbit plasma with the bacterial inoculum at $37^{\circ} \mathrm{C}$. The typical Staphylococcal isolates were identified based on colonial morphology and haemolysis reaction on Blood agar. Characteristic Staphylococcus isolates were round yellow colonies colonies on MSA (Figure 3) 


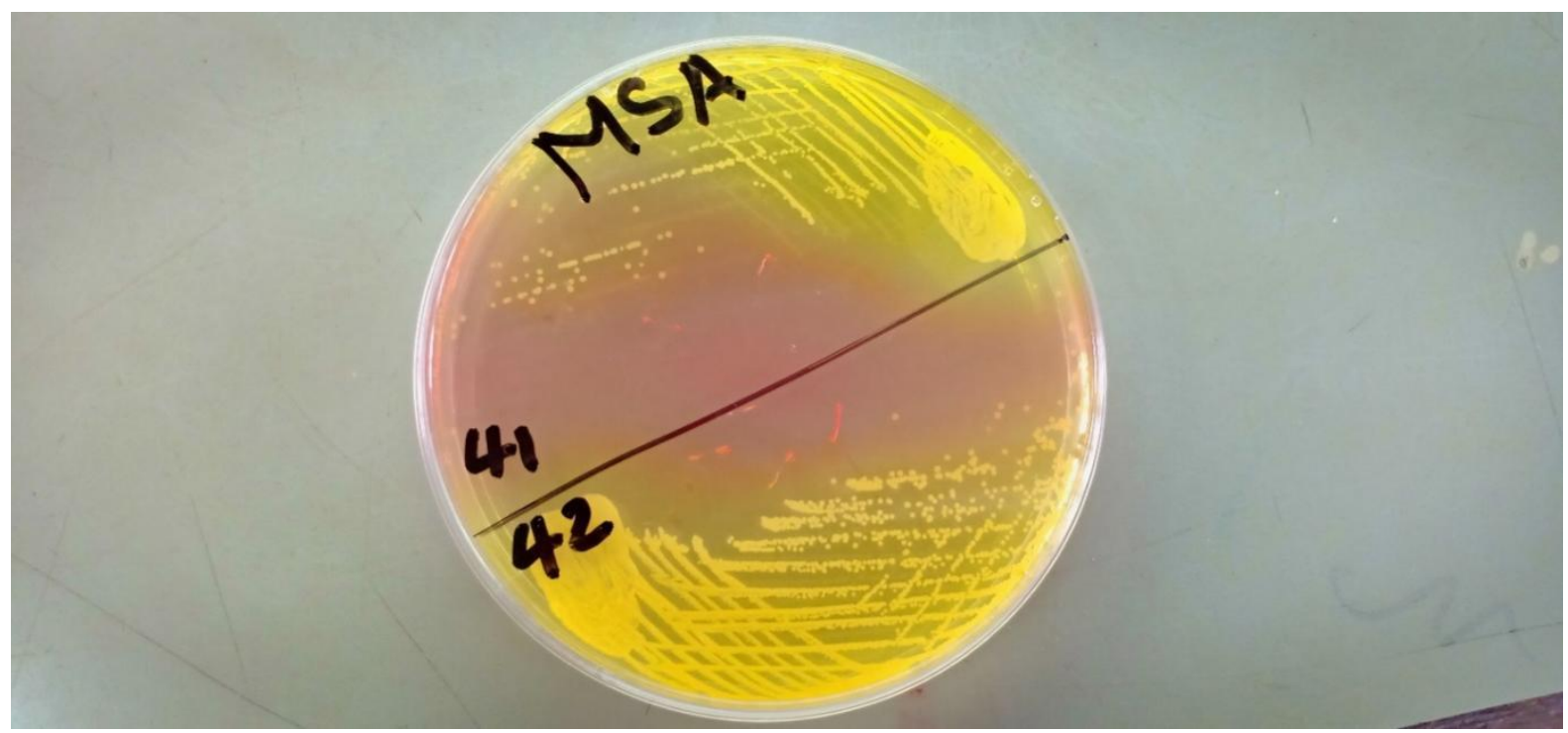

Figure 3. Yellow colonies of Staphylococcus isolates on MSA

\section{Confirmation of Staphylococcus aureus isolates by PCR}

The nuc gene of all isolates were amplified according to the protocol described by Wang et al., (1997). A total volume of $20 \mu$ l containing $5 \mu \mathrm{l}$ of DNA was presented for PCR. The primer sequence

nuc(F)GCGATTGATGGTGATACGGTT(R)CAA GCCTTGACGAACTAAAGC with 276bp was used. Thermal cycling reactions involved initial denaturation at $95^{\circ} \mathrm{C}$ for 3 minutes, followed by 35 cycles of denaturation at $95^{\circ} \mathrm{C}$ for 30 seconds, annealing at $52^{\circ} \mathrm{C}$ for 15 seconds, extension at $72^{\circ} \mathrm{C}$ for 1 minute and a final elongation at $72^{\circ} \mathrm{C}$ for 10 minutes. Amplification of the 416bp PCR products indicated the strain belonging to the genus Staphylococcus.

\section{Determination of antimicrobial resistance among Staphylococcus isolates}

Antibiotic susceptibility testing was done by the Kirby-Bauer disk diffusion method following the Clinical Laboratory Standards Institute (CLSI) guidelines (CLSI, 2017). Briefly, freshly cultured colonies in Trypticase Soy Agar (TSA) were used. About five colonies of the organisms were picked using a sterile wire-loop and suspended in $5 \mathrm{ml}$ of sterile normal saline which was then adjusted to a density approximately equal to 0.5 McFarland Opacity. Sterile swab of the suspension was used to plate streak the MHA.
Antibiotic disks were placed on the surface of the MHA using a disk dispenser and incubated at $37^{\circ} \mathrm{C}$ for 24 hours after which zones of growth inhibition $(\mathrm{mm})$ were measured and recorded. The readings were recorded as either susceptible, intermediate, or resistant based on the interpretative breakpoints by the veterinary Clinical Laboratory Standards Institute (CLSI) guidelines. The range of antimicrobial agents tested included: $10 \mu \mathrm{g}$ Ampicillin, $10 \mu \mathrm{g}$

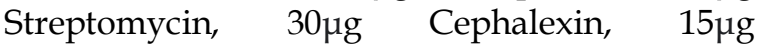
Erythromycin, $5 \mu \mathrm{g}$ Ciprofloxacin, $30 \mu \mathrm{g}$

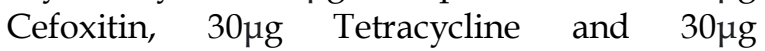
Chloramphenicol.

\section{Statistical data Analysis}

Data was entered into Microsoft Excel sheet 2016, coded and outliers removed before exporting to STATA version 13 software. Percentages of antibiotic resistant CoNS and S. aureus including the MDR Staphylococci were determined. Pattern analysis was used to generate the categories and presented using tables.

\section{Results}

\section{Distribution of camel samples}

The camel samples collected were distributed as shown in Table 1.

Prevalence of Staphylococci Species Isolated from raw camel milk 
Out of the 231 samples cultured overnight on Buffered Peptone Water (BPW) 133 (57.6\%) showed turbidity as a marker of successful recovery. A total of 52.6\% (122/231) samples had growth of round yellow colonies on MSA changing the colour of the media from pink to yellow as shown in Figure 3. This constituted 83.6\% CoPS and 16.4\% CoNS with CoPS being the most prevalent Staphylococcus. Out of all isolates further grown on Blood Agar, 122 (91.7\%) samples showed clear zones around the colonies indicating $\beta$-haemolysis. A total of $102 / 122$ $(83.6 \%)$ Staphylococcus isolates were coagulase positive as indicated by plasma clotting that remained intact when the test tubes were inverted and 20/122 (16.4\%) were coagulase negative in tube coagulase test. From the catalase test, $83(68.0 \%)$ of the isolates were catalase positive as shown by production of effervescence after reaction with hydrogen peroxide on the microscope slide. Table 2 below summarizes the culture and biochemical test results.

Table 1. Distribution of camels sampled from the sub Counties in Garissa County

\begin{tabular}{lcc}
\hline Sub County & Number of camels sampled & Total \% \\
\hline Fafi & 58 & $25.1 \%$ \\
Garissa & 25 & $10.8 \%$ \\
Dadaab & 23 & $10.0 \%$ \\
Lagdera & 83 & $35.9 \%$ \\
Balambala & 42 & $18.2 \%$ \\
Total & 231 & $100 \%$
\end{tabular}

Table 1. Recovery and biochemical tests of Staphylococcus species from raw camel milk

$\begin{array}{ll}\text { Culture and Biochemical } & \text { Number of positive } \\ \text { Characterization tests } & \text { samples }(\%)(\mathrm{N}=122)\end{array}$

\begin{tabular}{ll} 
Growth on $\mathrm{BPW}^{*}$ & $133(57.6 \%)$ \\
Growth on $\mathrm{MSA}^{*}$ & $122(91.7 \%)$ \\
$\beta$-Haemolysis & $102(83.6 \%)$ \\
Growth on $\mathrm{TSA}^{*}$ & $122(91.7 \%)$ \\
Coagulase & $93(82.3 \%)$ \\
Catalase & $83(68.0 \%)$ \\
\hline
\end{tabular}

*BPW- Buffered Peptone Water, MSA- Mannitol Salt Agar, TSA- Trypticase Soy Agar

Most of the isolates were highly sensitive to Chloramphenicol and Tetracycline both at (95.9\%) while high resistance to Cephalexin
(81.9\%) was observed among the isolates. The order of decreasing resistance in the 8 antimicrobial agents tested was; Cephalexin $(81.9 \%)$, Streptomycin (72.1\%), Ampicillin (33.6\%), Cefoxitin (10.7\%), Erythromycin (5.7\%), 
Ciprofloxacin $(4.1 \%)$, Tetracycline $(3.3 \%)$ and Chloramphenicol $(1.6 \%)$ as shown in Table 3. MRSA and MRCoNS were reported at $9.8 \%$ and $15 \%$ of the isolates respectively. A total of $43.4 \%$ of the isolates showed MDR while 39.3\% were resistant to 1 or 2 antimicrobials tested. An isolate was determined to be MDR by its resistance to at least 3 or more antimicrobial groups tested.

Table 3. Antibiotic susceptibility of 122 Staphylococci strains isolated from raw camel milk in Garissa County, Kenya

$\begin{array}{lccc}\text { Cephalexin } & 18.1 & - & 81.9 \\ \text { Streptomycin } & 27.9 & - & 72.1 \\ \text { Ampicillin } & 66.4 & - & 33.6 \\ \text { Cefoxitin } & 89.3 & - & 10.7 \\ \text { Erythromycin } & 83.6 & 10.7 & 5.7 \\ \text { Ciprofloxacin } & 87.7 & 8.2 & 4.1 \\ \text { Tetracycline } & 95.9 & 0.8 & 3.3 \\ \text { Chloramphenicol } & 95.9 & 2.5 & 1.6\end{array}$

\section{Comparison of antibiotic susceptibility of CoPS} and CoNS

Both coagulase positive and coagulase-negative Staphylococci isolates were highly sensitive to Tetracycline and Chloramphenicol. As shown in Table 4, CoPS were more resistant to most antimicrobials when compared with CoNS. A total of $72.5 \%$ (74/102) of the CoPS isolates were resistant to Cephalexin and $70 \%(14 / 20)$ CoNS isolates showed Cephalexin resistance, phenotypically. CoPS showed highest resistance to Streptomycin $(86.3 \%)$ while highest resistance among the CoNS was to Cephalexin (70\%). The Staphylococcal isolates showed moderate resistance to Ampicillin showing 34.3\% and 30\% resistance in CoPS and CoNS respectively.

Table 4. Comparison of overall resistance of 102 CoPS (Staphylococci aureus) and 20 CoNS isolates

\begin{tabular}{lcc}
\hline Antibiotic & CoPS resistant $\mathbf{n}(\%)$ & CoNS resistant $\mathbf{n}(\mathbf{\%})$ \\
\hline Cephalexin & $74(72.5)$ & $14(70)$ \\
Streptomycin & $88(86.3)$ & $12(60)$ \\
Erythromycin & $11(10.8)$ & $4(20)$ \\
Ciprofloxacin & $12(11.8)$ & $3(15)$ \\
Ampicillin & $35(34.3)$ & $6(30)$ \\
Cefoxitin & $10(9.8)$ & $3(15)$ \\
Tetracycline & $4(3.9)$ & $1(5)$ \\
Chloramphenicol & $2(2)$ & $3(15)$ \\
\hline
\end{tabular}




\section{Discussion}

The results show the presence of multidrug resistant CoNS and CoPS which were isolated from raw camel milk in the less studied ASAL region of Kenya. The pastoral community in the area consume raw camel milk without any heat treatment and this can pose a health hazard to the community.

Management of infectious diseases with antimicrobial agents has significantly improved animal health. However, the use of antibiotics has resulted in a selection for antimicrobial resistance by bacteria (GARP 2011). This can be through intrinsic resistance by microorganisms or acquired resistance through transfer of resistance plasmids (Testimonies and David, 2019). The increased resistance to antibiotics in the ASALs can be attributed to misuse, overdosing/under-dosing by pastoralists self medicating their camels as well as easy access to antibiotics over the counter (Lamuka et al., 2017).

In the current study, it was established that $52.6 \%$ $(122 / 231)$ of the bacteria isolated from analysed camel milk samples were Staphylococcus species. This constituted $83.6 \%$ CoPS and $16.4 \%$ CoNS with CoPS being the most prevalent Staphylococcus. These findings are similar to those reported by Aqib et al., (2017) who reported $74.5 \%$ Staphylococcus from camel milk in Pakistan with $87.2 \%$ being CoPS and $12.8 \%$ CoNS. The prevalence of Staphylococcus in the study were higher than those obtained by Elhag et al., (2013) who isolated $28.69 \%$ of Staphylococcus sp. in camel milk from Bar- Khartoum in Sudan and lower than the findings of Tsegalem et al., (2016) who isolated $89.8 \%$ Staphylococcus sp. from raw camel milk in Ethiopian Somali region State.

Remaz et al., (2015) in their study on Staphylococcus species in camel milk from Khartoum North in Sudan isolated 46.7\% Staphylococcus with $32.1 \%$ CoNS and $67.9 \%$ CoPS which agrees with the prevalence of Staphylococcus in this study with CoPS being the most common isolate. This was also similar to the findings of Varma and Prakesh (2016) who reported prevalence of CoPS at $62.5 \%$ and CoNS at $37.5 \%$ from raw camel milk from different regions of India.
The prevalence of Staphylococcus in the study was lower than that of Mbindyo et al., (2020) in their study on mastitis in dairy cattle in Embu and Kajiado Counties, Kenya who isolated $42.8 \%$ CoNS and $15.7 \%$ S. aureus. This may be attributed to the use of apparently healthy camels in this study. Gwida et al., (2018) in their study on evaluation of physiochemical properties and microbial quality of camel milk in Egypt isolated $42.8 \%$ Staphylococcus with $38.5 \%$ being CoPS which is significantly lower than the prevalence in this study. The prevalence of Staphylococcus in the study was also lower than the findings of Patrick et al., (2013) with 62\% Staphylococcus prevalence on raw and fermented camel milk from Kenya and Somalia. This may be attributed to raw milk from apparently healthy camels used in the study as compared to fermented milk.

The high prevalence of CoPS isolates was significantly higher than those of Hany et al., (2020) in their study in Saudi Arabia, where CoPS prevalence was $5 \%$ in pasteurized camel milk. This may be attributed to pasteurization process which eliminates most of the organisms in camel milk. However, this study is comparable to that of Al-Dughaym and Fadlelmul (2015) and Wanjohi et al. (2013). In contrast, Remaz and Nagwa (2015) in their study in Khartoum North in Sudan isolated $67.9 \%$ CoNS and $32.1 \%$ CoNS, mainly S. aureus. Mutua et al., (2017) reported higher CoNS isolates from nasal cavity of camels from Nakuru (36.84\%), Samburu (29.27\%) and Isiolo (22.43\%) Counties.

Multiple antibiotic testing of the isolated Staphylococcus showed highest resistance to cephalexin (81.9\%) and streptomycin (72.1\%) and lowest resistance to Chloramphenicol (1.6\%). These findings are agreeable to those of Mutua et al., (2017); who found highest susceptibility of Staphylococcus to Chloramphenicol, Kanamycin and Gentamycin (all at 100\%), followed by Cotrimoxazole and Streptomycin (34\%), followed by Ampicillin, Tetracycline and Sulphamethoxazole at $23 \%$ and $12 \%$ respectively.

Gitao et al, (2014) in their study of prevalence of common camel milk borne pathogens causing mastitis and their antibiotic resistance in North eastern Province in Kenya, identified S. aureus to be resistant to Ampicillin (0.30), Co-Trimoxazole (0.25), and Sulphamethoxazole (0.13) but 
sensitive to Gentamicin (1.89) and Tetracycline (1.08).

Multidrug resistance in the study $(43.4 \%)$ of the isolates resistant to at least 3 or more antimicrobial groups tested. This was higher than that of Mutua et al., (2017) who reported 30.5\% MDR in Staphylococus isolates from nasal cavity of camels in Samburu, Nakuru and Isiolo Counties.

Aqib et al., (2017) reported overall resistance of $54.7 \%$ from camel milk in Pakistan with resistance to Penicillins (90\%), Cephalosporins (77.5\%), Quinolones (77.5\%) and $92.7 \%$ to Sulphonamides which is similar to the findings in the study. Al-Thani and Al-Ali, (2014) also reported that Staphylococcus from different farms in Qatar was significantly resistant to tetracycline and ampicillin which did not concur with the study findings since highest resistance was recorded in cephalexin and streptomycin.

Njage et al., (2019) in their study on resistance patterns of $S$. aureus from raw and fermented camel milk from Kenya and Somali, observed Staphylococcal resistance to ampicillin (23.4\%) followed by streptomycin and Tetracycline (both at 10.6\%). Varma et al., (2017) reported high resistance by Staphylococcus to Ampicillin from camel milk from Bikaru District, India as compared to this study.

Aqib et al., (2017) reported $100 \%$ S. aureus sensitivity to Ciprofloxacin in their study on prevalence and antibiogram of Staphylococcus aureus from camel milk in Pakistan. This was higher than the findings reported in this study which show Ciprofloxacin had $87.7 \%$ sensitivity. Gitao et al., (2014) reported high sensitivity of isolates from raw camel milk to Tetracycline and Ampicillin which differed with the findings in the study. This may be attributed to the

\section{References}

Abd El-Razik, K. A., Arafa, A. A., Hedia, R. H., \& Ibrahim, E. S. (2017). Tetracycline resistance phenotypes and genotypes of coagulasenegative Staphylococcal isolates from apparently healthy camels sampled from the study.

Methicillin resistant Staphylococci have been reported in various foods of animal origin including camel and cattle milk (Soares et al., 2012; Njage et al., 2013; Silva et al., 2014). However, the surveillance of this resistance trait is imperative to Public Health and Veterinary Medicine.

\section{Conclusion}

Pastoral communities in ASALs of Northern Kenya use antimicrobial drugs extensively in the management of various camel udder infections (Omwenga et al., 2021). This drives a great risk of AMR which was observed in the study. AMR in the beta-lactams is high in the Staphylococcus isolates due to intensive use of these drugs by the pastoral community.

The study also showed that raw camel milk in Garissa County is contaminated with both AMR CoNS and $S$. aureus, including the MDRMRCoNS. Consumption of MDR-CoNS contaminated camel milk may pose a possible risk of transmission of these microorganisms between camels and in-contact humans.

It is recommended that continuous surveillance and monitoring of AMR Staphylococcus species, including the MDR-CoNS should be conducted in order to curb the emergence and spread of drug-resistant $S$. aureus and CoNS among the vulnerable population in the pastoral community.

\section{Acknowledgements}

The authors are grateful to all staff in the Department of Public Health, Pharmacology and Toxicology of the University of Nairobi for their help in this research. Special thanks go to Alfred Mainga for his guidance in the laboratory work.

bubaline mastitis in Egypt. Veterinary world, 10(6), 702.

Alekshun, M. N., \& Levy, S. B. (2007). Molecular mechanisms of antibacterial multidrug Resistance. Cell, 128(6), 1037-1050. 
Al-Thani R. F and Al-Ali F. (2012). Incidences and antimicrobial susceptibility profile of Staphylococcus species isolated from animals in different Qatari farms. African Journal of Microbiology Research 6:7454-7458.

Aqib, A. I., Ijaz, M., Durrani, A. Z., Anjum, A. A., Hussain, R., Sana, S., Farooqi SH., Hussain K., \& Ahmad, S. S. (2017). Prevalence and antibiogram of Staphylococcus aureus, a camel mastitogen from Pakistan. Pakistan Journal of Zoology, 49(3).

Becker, K., Heilmann, C., \& Peters, G. (2014). Coagulase-negative Staphylococci. Clinical microbiology reviews, 27(4), 870-926.

Bennett, R. W., Hait, J. M., \&Tallent, S. M. (2013). Staphylococcus aureus. Guide to foodborne pathogens, 26-44.

Beyene, T., Hayishe, H., Gizaw, F., Beyi, A. F., Abunna, F., Mammo, B., Ayana, D., Waktole, H \& Abdi, R. D. (2017). Prevalence and antimicrobial resistance profile of Staphylococcus in dairy farms, abattoir and humans in Addis Ababa, Ethiopia. BMC research notes, 10(1), 1-9.

Bhargava, K., \& Zhang, Y. (2012). Multidrug-resistant coagulasenegative Staphylococci in food animals. Journal of applied microbiology, 113(5), 1027-1036.

Chajęcka-Wierzchowska, W., Zadernowska, A., Nalepa, B., Sierpińska, M., \& ŁaniewskaTrokenheim, Ł. (2015). Coagulasenegative Staphylococci (CoNS) isolated from ready-to-eat food of animal origin-phenotypic and genotypic antibiotic resistance. Food microbiology, 46, 222-226.

Cherifi, S., Byl, B., Deplano, A., Nonhoff, C., Denis, O., \& Hallin, M. (2013).
Comparative epidemiology of Staphylococcus epidermidis isolates from patients with catheter-related bacteremia and from healthy volunteers. Journal of clinical microbiology, 51(5), 1541-1547.

De Buck, J., Ha, V., Naushad, S., Nobrega, D. B., Luby, C., Middleton, J. R., De Vliegher, S \& Barkema, H. W. (2021). Non-aureus Staphylococci and Bovine Udder Health: Current Understanding and Knowledge Gaps. Frontiers in veterinary science, 8,360 .

Demple, B. (2005). The Nexus of oxidative stress responses and antibiotic resistance mechanisms in Escherichia coli and Salmonella. In Frontiers in Antimicrobial Resistance (pp. 191-197). American Society of Microbiology.

Dos Santos, F. F., Mendonça, L. C., de Lima Reis, D. R., de SáGuimarães, A., Lange, C. C., Ribeiro, J. B., Machado M. A., \& Brito, M. A. V. P. (2016). Presence of mecA-positive multidrug-resistant Staphylococcus epidermidis in bovine milk samples in Brazil. Journal of dairy science, 99(2), 1374-1382.

Duran, N., Ozer, B., Duran, G. G., Onlen, Y., \&Demir, C. (2012). Antibiotic resistance genes \& susceptibility patterns in Staphylococci. The Indian journal of medical research, 135(3), 389.

Egyir, B.,Guardabassi, L., Sørum, M., Nielsen, S. S., Kolekang, A., Frimpong, E., Addo K K., Newman M. J., \& Larsen, A. R. (2014). Molecular epidemiology and antimicrobial susceptibility of clinical Staphylococcus aureus from healthcare institutions in Ghana. PloS one, 9(2), e89716.

Elhag, W. I., Saeed, H. A., El Fadhil, E. O., \& Ali, A. S. (2013). Prevalence of rotavirus and adenovirus 
associated with diarrhea among displaced communities in Khartoum, Sudan. BMC infectious diseases, 13(1), 1-6.

Feßler, A. T., Billerbeck, C., Kadlec, K., \& Schwarz, S. (2010). Identification and characterization of methicillinresistant coagulase-negative Staphylococci from bovine mastitis. Journal of antimicrobial chemotherapy, 65(8), 1576-1582.

Fey P.D. and Olson M.E., (2010). Current concepts in biofilm formation of Staphylococcus epidermidis. Future Microbiology 5, 917-933.

Foster TJ, Geoghegan JA, Ganesh VK and Höök M. (2014). Adhesion, invasion and evasion: the many functions of the surface proteins of Staphylococcus aureus. Nat Rev Microbiol 12(1):49-62.

Fowoyo, P. T., \& Ogunbanwo, S. T. (2017). Antimicrobial resistance in coagulase-negative Staphylococci from Nigerian traditional fermented foods. Annals of clinical microbiology and antimicrobials, 16(1), 1-7.

Frey, Y., Rodriguez, J. P., Thomann, A., Schwendener, S., \&Perreten, V. (2013). Genetic characterization of antimicrobial resistance in coagulase-negative Staphylococci from bovine mastitis milk. Journal of dairy science, 96(4), 2247-2257.

GARP (Global Antibiotic Resistance Partnership-Kenya Working Group) (2011): Situation Analysis and Recommendations: Antibiotic Use and Resistance in Kenya. Washington, DC and New Delhi: Center for Disease Dynamics Economics \& Policy.

Gitao G. C., Wanjohi, M., Gitari, R., Akweya, B. and Okoth, M. W. (2014). The Prevalence of Common Milk Borne Pathogens of Camelus
Mastitis Origin and their Antibiotic Resistance in North Eastern Province, Kenya American Journal of Research Communication 21: 5366.

Kateete D.P, Kimani C.N and Katabazi F.A. (2010). Identification of Staphylococcus aureus: DNase and Mannitol salt agar improve the efficiency of the tube coagulase test. Ann ClinMicrobiolAntimicrob 9:23.

Khan J.A., Rathore R.S., Ahmad I. and Khan S. (2011). Molecular Strategies: Detection of

Foodborne Bacterial Pathogens. In: Ahmad, I., Ahmad F., Pitchel, J. (eds). Microbes and Microbial Technology. Springer, NewYork, pp 189-206.

Klibi, A., Maaroufi, A., Torres, C., \&Jouini, A. (2018). Detection and characterization of methicillinresistant and susceptible coagulasenegative Staphylococci in milk from cows with clinical mastitis in Tunisia. International journal of antimicrobial agents, 52(6), 930-935.

Kotsakis, S. D., Tzouvelekis, L. S., Zerva, L., Liakopoulos, A., \& Petinaki, E. (2012). Staphylococcus lugdunensis strain with a modified PBP1A/1B expressing resistance to $\beta$ lactams. European journal of clinical microbiology \& infectious diseases, 31(2), 169-172.

Lamuka, P. O., Njeruh, F. M., Gitao, G. C., \&Abey, K. A. (2017). Camel health management and pastoralists' knowledge and information on zoonoses and food safety risks in Isiolo County, Kenya. Pastoralism, 7(1), 1-10.

Mahato, S., Mistry, H. U., Chakraborty, S., Sharma, P., Saravanan, R., \& Bhandari, V. (2017). Identification of variable traits among the 
methicillin resistant and sensitive coagulase negative Staphylococci in milk samples from mastitic cows in India. Frontiers in microbiology, 8, 1446.

Melo, D. A., Motta, C. C., Rojas, A. C. C. M., Soares, B. S., Coelho, I. S., Coelho, S. M. O., \& Souza, M. M. S. (2018). Characterization of CoagulaseNegative Staphylococci and phenogenotypic beta lactam resistance evaluation in samples from bovine Intramammary infection. ArquivoBrasileiro de MedicinaVeterinária Zootecnia, 70(2), 368-374.

Mbindyo, C. M., Gitao, G. C., \& Mulei, C. M. (2020). Prevalence, etiology, and risk factors of mastitis in dairy cattle in Embu and Kajiado Counties, Kenya. Veterinary medicine international, 2020.

Mukokinya, M. M. A., Opanga, S., Oluka, M., \& Godman, B. (2018). Dispensing of antimicrobials in Kenya: A cross-sectional pilot study and its implications. Journal of research in pharmacy practice, $7(2)$, 77 .

Mutua, J. M., Gitao, C. G., Bebora, L. C., \&Mutua, F. K. (2017). Antimicrobial resistance profiles of bacteria isolated from the nasal cavity of camels in Samburu, Nakuru, and Isiolo Counties of Kenya. Journal of veterinary medicine, 2017.

Njage, P. M. K., Dolci, S., Jans, C., Wangoh, J., Lacroix, C., \& Meile, L. (2013). Phenotypic and genotypic antibiotic resistance patterns of Staphylococcus aureus from raw and spontaneously fermented camel milk. European Journal of Nutrition \& Food Safety, 87-98.

Omwenga, I., Aboge, G. O., Mitema, E. S., Obiero, G., Ngaywa, C., Ngwili, N., Wamwere, G., Wainaina, M. \&Bett, B. (2021). Antimicrobial Usage and
Detection of Multidrug-Resistant Staphylococcus aureus, Including Methicillin-Resistant Strains in Raw Milk of Livestock from Northern Kenya. Microbial Drug Resistance.

Opintan, J. A., Newman, M. J., Arhin, R. E., Donkor, E. S., Gyansa-Lutterodt, M., \& Mills- Pappoe, W. (2015). Laboratory-based nationwide surveillance of antimicrobial resistance in Ghana. Infection and drug resistance, 8, 379 .

Osman, K., Badr, J., Al-Maary, K. S., Moussa, I. M., Hessain, A. M., Girah, Z., Amin, M.S., Abo-shama, U.H., Orabi, A \&Saad, A. (2016). Prevalence of the antibiotic resistance genes in coagulasepositive-and negativeStaphylococcus in chicken meat retailed to consumers. Frontiers in microbiology, 7, 1846.

Otto M., (2013). Coagulase-negative Staphylococci as reservoirs of genes facilitating MRSA infection. Bioessays35, 4-11.

Podkowik, M., Park, J. Y., Seo, K. S., Bystroń, J., \&Bania, J. (2013). Enterotoxigenicpotential of coagulase-negative Staphylococci. International journal of food microbiology, 163(1), 34-40.

Pyatov, V., Vrtková, I., \& Knoll, A. (2017). Detection of selected antibiotic resistance genes using multiplex PCR assay in mastitis pathogens in the Czech Republic. ActaVeterinaria Brno, 86(2), 167-174.

Ryan, K. J., \& Ray, C. G. (2004). Medical microbiology. McGraw Hill, 4, 370.

Remaz, M., \& Elhag, N. B (2015). Characterization of Staphylococcus species and Detection of Methicillin Resistant Staphylococcus aureus in Camel Milk at Khartoum North, Sudan. 
Sampimom O.C., Lam TJ., Mevius DJ..Schukken YH and Zadoks RN., (2011). Antimicrobial susceptibility of coagulase-negative Staphylococci isolated from bovine milk samples. Veterinary Microbiology150, 173-179.

Sangeda, R. Z., Lifumo, S., Muigai, A. W., Waiyaki, P. G., \&Kariuki, S. (2017). Antimicrobial susceptibility patterns of Staphylococcus aureus and coagulase negative Staphylococci isolated from humans in Nairobi, Kenya. African Journal of Microbiology Research, 11(18), 705-711.

Schoenfelder, S. M., Lange, C., Eckart, M., Hennig, S., Kozytska, S., \& Ziebuhr, W. (2010). Success through diversity-how Staphylococcus epidermidis establishes as a nosocomial pathogen. International Journal of medical microbiology, 300(6), 380-386.

Silva, N. C. C., Guimarães, F. F., Manzi, M. P., Júnior, A. F., Gómez-Sanz, E., Gómez, P., Langoni, H., Rall, V.L.M \& Torres, C. (2014). Methicillinresistant Staphylococcus aureus of lineage ST 398 as cause of mastitis in cows. Letters in applied microbiology, 59(6), 665-669.

Simojoki, H., Hyvönen, P., Plumed Ferrer, C., Taponen, S. and Pyörala, S. (2012). Is the biofilm formation and slime producing ability of coagulase-negative Staphylococci associated with the persistence and severity of intramammary infection.Vet Microbiol 158, 344352.

Spaulding, A. R., Salgado-Pabón, W., Kohler, P. L., Horswill, A. R., Leung, D. Y., \&Schlievert, P. M. (2013). Staphylococcal and Streptococcal superantigen exotoxins. Clinical microbiology reviews, 26(3), 422-447.
Soares, L. C., Pereira, I. A., Pribul, B. R., Oliva, M. S., Coelho, S. M., \& Souza, M. (2012). Antimicrobial resistance and detection of mecA and blaZ genes in coagulase negative Staphylococcus isolated from bovine mastitis. PesquisaVeterináriaBrasil eira, 32(8), 692-696.

Srednik, M. E., Tremblay, Y. D., Labrie, J., Archambault, M., Jacques, M., FernándezCirelli, A., \&Gentilini, E. R. (2017). Biofilm formation and antimicrobial resistance genes of coagulase-negative Staphylococci isolated from cows with mastitis in Argentina. FEMS microbiology letters, 364(8), fnx001.

Starlander, G., Börjesson, S., GrönlundAndersson, U., Tellgren-Roth, C., \& Melhus, ̊. (2014). Cluster of infections caused by methicillinresistant Staphylococcus pseudintermedius in humans in a tertiary hospital. Journal of clinical microbiology, 52(8), 3118-3120.

Toroitich, K. C., Gitau, G. K., Kitala, P. M., \& Gitao, G. C. (2017). The prevalence and causes of mastitis in lactating traditionally managed one-humped camels (Camelus dromedarius) in West Pokot County, Kenya. Livestock Research for Rural Development, 29(4), 62.

Toroitich, K. C. (2012). Camel health problems affecting milk production in Garissa.

Toutain, P. L., Ferran, A. A., BousquetMelou, A., Pelligand, L., \& Lees, P. (2016). Veterinary medicine needs new green antimicrobial drugs. Frontiers in microbiology, 7, 1196.

Van Kinh, N., Wertheim, H. F., Thwaites, G. E., Khue, L. N., Thai, C. H., Khoa, Nguyen $\mathrm{Vu}$

Trung, Derrick Crook, and H. Rogier van Doorn (2017). Developing an 
antimicrobial resistance reference laboratory and surveillance programme in Vietnam. The Lancet Global Health, 5(12), e1186-e1187.

Verma, M. and Prakash, A. (2016). Incidence of Coagulase in raw camel milk from different regions of India: A possible threat to Positive Staphylococcus Diabetic Consumers, 7(4), 121-126.

Wanjohi, M., Gitao, C. G., \&Bebora, L. (2013). Subclinical mastitis affecting hygienic quality of marketed camel milk from North-Eastern Province, Kenya. Microbiology Research International, 1(1), 6-15.
World Health Organization. (2014). Antimicrobial resistance: Global report on surveillance. World Health Organization.

Youssif, N. H., Hafiz, N. M., Halawa, M. A., \& Aziz, H. M. (2021). Genes conferring antimicrobial resistance in cattle with subclinical mastitis. Bulgarian Journal of Veterinary Medicine, 24(1).

Zdolec, N., Dobranić, V., Butković, I., Koturić, A., Filipović, I., \& Medvid, V. (2016). Antimicrobial susceptibility of milk bacteria from healthy and drug-treated cow udder. Vet. Arhiv, 86(2), 163-172. 